Meta

Journal des traducteurs

Translators' Journal

\title{
Colección Panamericana, traducción peninsular: los polos de la representación y de la inteligibilidad en un proyecto editorial
}

\section{Clara Foz et Lili Atala}

Volume 64, numéro 2, août 2019

URI : https://id.erudit.org/iderudit/1068202ar

DOI : https://doi.org/10.7202/1068202ar

Aller au sommaire du numéro

\section{Éditeur(s)}

Les Presses de l’Université de Montréal

ISSN

0026-0452 (imprimé)

1492-1421 (numérique)

Découvrir la revue

Citer cet article

Foz, C. \& Atala, L. (2019). Colección Panamericana, traducción peninsular: los polos de la representación y de la inteligibilidad en un proyecto editorial. Meta, 64(2), 446-466. https://doi.org/10.7202/1068202ar

\section{Résumé de l'article}

Dans les années 1930 et 1940, la guerre civile espagnole ainsi que la crise de l'après-guerre en Europe ont donné lieu à une migration des activités d'édition de l'Espagne vers l'Amérique latine. Dans ce contexte, la production écrite américaine au sens large a occupé pour la première fois une place de choix auprès des éditeurs, ce dont témoigne à cette époque la prolifération de collections de « classiques américains ». Cet article porte sur la Colección Panamericana de W. M. Jackson (1945) et montre que si le discours entourant cette collection est explicitement celui d'une singularité panaméricaine, la traduction des textes choisis pour représenter le Brésil, le Canada, les États-Unis et Haïti est quant à elle enracinée dans un panhispanisme qui proscrit les variétés d'espagnol des Amériques. Sont mises au jour et analysées les caractéristiques de la maison Jackson, une entreprise étasunienne transnationale spécialisée dans la vente à grande échelle de collections et qui, en tant que telle, est éloignée du milieu intellectuel hispanoaméricain. Les volumes traduits sont considérés à la lumière des instructions fournies par cet éditeur dans un manuel de style dont l'objectif déclaré est d'assurer que les textes traduits soient accessibles à tous les hispanophones. Finalement, à travers certains exemples, est illustrée la contradiction entre la représentation des réalités américaines présentes dans les textes traduits et leur exposition dans une langue supposément neutre. 


\title{
Colección Panamericana, traducción peninsular: los polos de la representación y de la inteligibilidad en un proyecto editorial
}

\author{
CLARA FOZ \\ Université d'Ottawa, Ottawa, Canadá \\ cfoz@uottawa.ca
}

LILI ATALA

Université d'Ottawa, Ottawa, Canadá

lata1043@uottawa.ca

\begin{abstract}
RÉSUMÉ
Dans les années 1930 et 1940, la guerre civile espagnole ainsi que la crise de l'aprèsguerre en Europe ont donné lieu à une migration des activités d'édition de l'Espagne vers l'Amérique latine. Dans ce contexte, la production écrite américaine au sens large a occupé pour la première fois une place de choix auprès des éditeurs, ce dont témoigne à cette époque la prolifération de collections de «classiques américains». Cet article porte sur la Colección Panamericana de W. M. Jackson (1945) et montre que si le discours entourant cette collection est explicitement celui d'une singularité panaméricaine, la traduction des textes choisis pour représenter le Brésil, le Canada, les États-Unis et Haïti est quant à elle enracinée dans un panhispanisme qui proscrit les variétés d'espagnol des Amériques. Sont mises au jour et analysées les caractéristiques de la maison Jackson, une entreprise étasunienne transnationale spécialisée dans la vente à grande échelle de collections et qui, en tant que telle, est éloignée du milieu intellectuel hispanoaméricain. Les volumes traduits sont considérés à la lumière des instructions fournies par cet éditeur dans un manuel de style dont l'objectif déclaré est d'assurer que les textes traduits soient accessibles à tous les hispanophones. Finalement, à travers certains exemples, est illustrée la contradiction entre la représentation des réalités américaines présentes dans les textes traduits et leur exposition dans une langue supposément neutre.
\end{abstract}

\section{ABSTRACT}

In the 1930's and '40's the Spanish Civil war and the crisis brought upon by WWII in Europe resulted in the migration of Spanish-language publishing activities from Spain to Latin America. In this context, the continent and its literary production found themselves for the first time at the centre of editorial preoccupations, as evidenced by the proliferation of series showcasing American Classics. This article examines one such series, the Colección Panamericana of W. M. Jackson (1945), arguing that, although the series explicitly promotes a discourse of Pan-Americanism, the translation practices evidenced in the texts chosen to represent Brazil, Canada, Haiti and the United States thoroughly abide by a pan-hispanism which forbids the use of American varieties of Spanish. We explore the characteristics of the Jackson publishing company-its transnationalism, its intellectual distance from Hispanic America as a U.S. publisher, and its exclusive publication of series in order to guarantee high-volume sales. We then look at those volumes of the Colección Panamericana that consist of translations in light of the style guide provided by the company for its editors and translators, which emphasizes the importance of providing material that is linguistically accessible to all Spanish speakers. Finally, we take examples from the translations to illustrate the contradiction between the representation of American reality/ies contained in the texts and its/their expression in a supposedly neutral Spanish. 


\section{RESUMEN}

La guerra civil española y los conflictos en Europa entre las décadas de 1930 y 1940 resultaron en un traslado de las actividades editoriales del mundo hispánico desde España hacia América. En este contexto, la producción escrita de América se volvió central en los proyectos editoriales; la proliferación de colecciones cuyo fin era reunir los clásicos americanos es muestra de ello. Mediante el estudio de la Colección Panamericana de W. M. Jackson (1945) este artículo argumenta que, si bien esta colección promueve explícitamente un discurso identitario panamericano, en lo que toca a la traducción, es un producto enraizado en un panhispanismo que proscribe el uso de las variedades del español de las Américas. El artículo explora las características particulares de la casa Jackson: su carácter de empresa trasnacional, su lejanía de la intelectualidad hispanoamericana al ser una editorial estadounidense y su exclusiva publicación de colecciones con el fin de garantizar ventas por volumen. Asimismo, analiza los tomos de la Colección Panamericana, en particular los que se ofrecen en traducción, a la luz de los lineamientos expuestos por la editorial en un manual de estilo destinado a sus editores y traductores, en donde se insiste en la importancia de ofrecer un material lingüísticamente accesible a todos los hispanohablantes. Por último, mediante algunos ejemplos, muestra la contradicción entre la representación de la realidad americana presente en los textos traducidos y su exposición en una voz supuestamente neutra.

\section{MOTS CLÉS/KEYWORDS/PALABRAS CLAVE}

traduction panhispanique, panaméricanisme, éditeurs transnationaux, classiques américains, espagnol neutre

Pan-Hispanic translation, pan-Americanism, transnational publishing, American classics, neutral Spanish

traducción panhispánica, panamericanismo, editores trasnacionales, clásicos americanos, español neutro

\section{Introducción}

En las primeras líneas de un manual de instrucciones para los traductores y correctores de la que alguna vez fuera una importante editorial en Latinoamérica se advierte: «Considere, pues, que escribe para ciento veinte millones de hispanohablantes, y que de la corrección y propiedad de su lenguaje dependerá el ser bien comprendido por todos» (Náñez e Izquierdo 1945: 4). Con tal sencillez se enuncia la tarea encomendada a los traductores que en los años 40 del siglo xx harían parte del periodo más activo de la industria editorial en Hispanoamérica (De Diego 2006). Las instrucciones antes citadas pertenecieron a la editorial W. M. Jackson, conocida en Latinoamérica antes que nada por su colección Clásicos Jackson. Quizás menos célebre, la Colección Panamericana (1945) del mismo editor nos interesa pues constituye el punto de toque de la editorial con uno de los debates ideológicos de su tiempo, en este caso, el de la afirmación de la identidad americana. A dicha colección y al singular papel de la traducción en ella dedicaremos este trabajo.

El estudio de la traducción en esta colección pone de manifiesto la interacción de las agendas políticas, mercantiles e ideológicas en el campo editorial latinoamericano de mediados del siglo XX. En los paratextos de la colección, especialmente en el breve «Propósito» (Anón. 1945) ${ }^{1}$ que abre cada volumen, observamos un afán incluyente y exhaustivo ya que se pretende dar a conocer obras que representen «lo mejor de la producción escrita de cada república del continente» (Anón. 1945: v) precedidas por «Reseñas Culturales» de cada país. Sin embargo, en la medida en que 
nos acercamos a las traducciones, diversas tensiones empiezan a surgir y se revela que las estrategias de traducción están muy lejos del discurso de los paratextos: si bien en ellos se hace hincapié en la independencia cultural americana, mediante el uso dominante del español peninsular en las traducciones se despoja a los textos de aquello que los editores denominan «la expresión genuina de nuestros países» (Anón. 1945: v). Estamos ante un caso en donde una supuesta búsqueda de la inteligibilidad del material traducido del inglés, del francés y del portugués mediante el uso de un español marcadamente peninsular, entendido aquí como lengua neutra, no sólo contradice la diversidad lingüística «natural» del repertorio hispanoamericano presente en la colección, sino que choca con la reivindicación de la singularidad americana, verdadero leitmotiv de las «Reseñas Culturales» y de la colección en general.

\section{2. «Libros por metros...»: la Colección Panamericana en contexto}

W. M. Jackson ${ }^{2}$ fue pionera en Latinoamérica en la venta de libros por catálogo y, como se ha dicho, especialista en la venta de colecciones (Lehmann-Haupt 1939: 254; Hallewell 1982/2005: 367). Esta casa editorial estadounidense de envergadura trasnacional es comparable a lo que en su momento fue la famosa editorial Appleton, que desde mediados del siglo XIX vendía libros en América Latina, aprovechando los incipientes mercados que ofrecían las nuevas repúblicas. El alcance de las actividades de W. M. Jackson se evidencia en la portada de los volúmenes de la Colección Panamericana donde se incluye debajo del nombre de la editorial una lista de ciudades: Buenos Aires, New York, México, Caracas, Montevideo, Lima, Santiago de Chile, Río de Janeiro, Puerto Rico, Habana y Bogotá.

Walter Montgomery Jackson inició sus actividades mediante la venta por suscripción de la decimotercera edición de la Enciclopedia Británica en el mundo anglosajón y desde las primeras décadas del siglo XX sus hijos expandieron las actividades de la casa llevando los mismos métodos de venta por suscripción a Latinoamérica (Lehmann-Haupt 1939: 254). Todo indica que la consigna de esta editorial era la venta exclusiva de colecciones. Por ejemplo, en Brasil, donde W. M. Jackson competía con la editorial José Olympio, la obtención por parte del editor estadounidense de los derechos de la obra de Machado de Assis en 1934 significó la venta exclusiva de su obra en volúmenes y dio lugar a un monopolio que afectaba tanto al resto de los editores como al mismo público lector:

A Jackson, porém, sempre trabalhara exclusivamente com coleções, ao passo que as edições em muitos volumes da José Olympio eran lançadas, inicialmente em volumes separados, a não ser nos poucos casos em que a coleção consistia de uma única obra. Essa foi uma política deliberada. Quando a Garnier foi vendida a Ferdinand Briguiet [...] José Olympio pediu a um advogado amigo que procurasse negociar os valiosos direitos de publicação de Machado de Assis. Ficou estupefacto ao saber que, debido à lentidão do advogado, eles haviam sido vendidos à Jackson. Sua decepção não foi tanto por ter perdido uma mina de ouro, mas por temer que a política de Jackson de vender apenas coleções completas estancasse o crescimento do natural interesse em Machado de Assis através da compra casual de volumes avulsos (Hallewell 1982/2005: 467).

No podemos olvidar que las actividades de Jackson en estos años se inscriben en un contexto histórico en que la internacionalización de las prácticas editoriales no era exclusiva de los Estados Unidos ni tampoco un fenómeno reciente. De hecho, 
como lo indica Fernández Moya (2008: 5) ${ }^{3}$, «las plazas latinoamericanas estaban dominadas a comienzos del siglo XX por editoriales francesas, alemanas, inglesas y estadounidenses que publicaban en castellano». La actividad en América Latina de editoriales como Garnier o Bouret, por ejemplo, estuvo marcada por una intensa competencia y una lucha constante por conservar su lugar en este mercado que cada vez era más lucrativo, ya que se beneficiaba, entre otras cosas, de mejores medios de comunicación, de una creciente concentración urbana y de los programas de alfabetización puestos en práctica por diversos gobiernos (Fernández 1998: 166). Para las editoriales, las colecciones y las enciclopedias, distribuidas y vendidas a gran escala, representaban un producto predilecto y una fuente de ganancias, quizá no garantizadas, pero sí previsibles.

De hecho, las colecciones eran, hacia 1945, un fenómeno muy difundido en la América de habla hispana. Hubo muchas y de todo tipo: dedicadas a la producción de un solo país, a un género, a una lengua, a los clásicos universales, por mencionar tan sólo algunos de los ejemplos más sobresalientes. No obstante, si algo distinguió a las colecciones de la década de los 40 fue la predilección por el tema americano. Al parecer de un crítico español de la época,

Muy recientes suelen ser las colecciones dedicadas por los pueblos hispanoamericanos a sus propios clásicos, con predominio de las de tipo histórico y se aprecia todavía la ausencia de las que podrían y deberían dedicarse exclusivamente a los escritores del periodo español. (Díaz 1950: 104)

La aparición de colecciones como Grandes Escritores de América (Losada, 1939), Biblioteca Americana (FCE, 1942), El pensamiento de América (SEP, 1942), Nuestra América (Nova, 1943), Tierra Firme (FCE, 1945) y la propia Colección Panamericana, parece confirmar lo anterior. Sin embargo, a pesar de que el título de estas colecciones sugiere una línea similar, las diferencias en sus catálogos revelan diversas definiciones de América. Algunas de ellas, incluso, explicitaron sus distintas tomas de posición. En el folleto con que se presentó la colección Biblioteca Americana, por ejemplo, se aclara su particular uso del término América:

[...] se publicará bajo el título general de Biblioteca Americana, evocador de uno de los constructores espirituales de nuestra América: Andrés Bello. Siguiendo su precedente, hemos empleado el nombre en un sentido limitado, refiriéndolo especialmente a la América hispánica. (Weinberg 2014: 72)

Es de notar que curiosamente esta noción de lo hispánico incluía también a Brasil:

Preferimos esta denominación a las de América latina e Iberoamérica -más conocidas, pero no más exactas- para designar el conjunto de los países americanos de habla española y portuguesa, de acuerdo con el criterio de Pedro Henríquez Ureña. (Weinberg 2014: 73)

Si bien no todas las colecciones de la época hicieron explícita su delimitación de América, ésta quedaba clara en la selección de textos que incluían. En este sentido, la comprensión de lo americano pasaba necesariamente por aquello que decidían traducir. En cuanto a la selección de autores hispanoamericanos, por lo general, no variaban mucho estas colecciones (Bolívar, Martí, Sarmiento, Rodó, Darío...), pero se diferenciaban en la incorporación de Brasil, la apertura al Norte y al Caribe, y la inclusión de las tradiciones indígenas. En estas posturas, se observa la variedad de normas preliminares (Toury 1995) que reflejan las formas de pensar el hemisferio y 
se materializan en objetos editoriales dentro de los cuales se reactiva la noción de lo clásico, aplicándola a la realidad americana.

Los discursos identitarios que sirven de trasfondo a estos proyectos se adoptan desde un continuum de posiciones. La desconexión entre el discurso incluyente de los prólogos de la Panamericana y las estrategias usadas en sus traducciones revela que, en el caso de Jackson, la bandera del Panamericanismo se adopta desde una postura estadounidense con claras aspiraciones mercantiles. No obstante, al otro extremo se encuentran las colecciones para las que la inserción en el debate identitario implicaba un serio compromiso con la región. En las cartas de Norberto Frontini, personaje clave para la colección Tierra Firme del FCE, que recoge Sorá (2008) se evidencia la voluntad de unir mediante un proyecto editorial a los países latinoamericanos en vista de la crisis que se vivía en Europa:

La necesidad de sustituir los monólogos de los pueblos latinoamericanos por un diálogo frecuente y provechoso que supere el tratagismo [sic] diplomático es cada vez más urgente. [...] Brasil es un difícil problema y su soledad -desconocimiento de los demás y particularmente argentino- dentro del continente está lleno de peligros. Debemos prepararnos para establecer entendimientos esenciales entre ese país, lleno a su vez de complicaciones, y los de origen español. El después de la guerra es para nuestros países cada vez más sombrío. El propósito de la editorial ha sido, por eso mismo, muy bien visto (Frontini en Sorá 2008: 561).

Este testimonio permite pensar en las colecciones -y la traducción en ellas- como proyectos clave para la comunicación entre los países, y muestra, en algunos casos, la primacía de las motivaciones políticas.

La Colección Panamericana, como ya indicamos, no fue parte del fenómeno antes citado; más bien se asociaba directamente con los otros productos de la editorial Jackson, que era conocida por su afán mercantil en la región y, por lo mismo, menospreciada por los intelectuales latinoamericanos de la época. Se pueden citar dos ejemplos al respecto: refiriéndose a la colección Clásicos Jackson, Alfonso Reyes (citado en Venier 2008: 215) declara «tengo sobre todo trabado en los puntos de la pluma un ridículo ensayito sobre literatura epistolar para esas ediciones antológicas de la Casa Jackson (libros por metros, libros como mueble)». A pesar del desdén hacia los productos de Jackson, sea la colección Clásicos Jackson o la Panamericana, dicha editorial pudo contar con la colaboración de reconocidos intelectuales como el mismo Reyes ${ }^{4}$. En una de las numerosas cartas intercambiadas entre Daniel Cosío Villegas, director del FCE, y Pedro Henríquez Ureña a propósito de la planificación de la Biblioteca Americana, se alude a las gestiones necesarias entre una amplia red de intelectuales latinoamericanos para la conformación de la colección. También se menciona con espíritu revanchista que esta colección representaría un desbancamiento del americanismo à la Jackson, pues «de llevarse a cabo, la colección panamericana quedará a la altura de una zapatilla» (citado en Weinberg 2014: 57).

Si el denominado americanismo representaba para los países de habla hispana un proyecto intelectual, la versión que ofrece Jackson del panamericanismo es la de un panamericanismo, que "pasa de manera obligada por los Estados Unidos» (Ardao 1993: 157) y tiene un trasfondo más bien económico, ya que se inscribe en una época de expansión económica de dicho país y en su búsqueda de nuevos mercados (Ardao 1993: 159). Sin embargo cabe señalar que el panamericanismo cuenta con una larga historia, y ha servido a ideales diversos: en el periodo posterior a las independencias 
sirvió para cimentar la identidad de las nuevas naciones americanas en contraposición con las metrópolis coloniales. Este fue el panamericanismo de Simón Bolívar, enraizado en un nacionalismo criollo que excluía a Estados Unidos (Park 2014: 5). A finales del siglo XIX, la creación de la Pan American Union (1890) marcó la apropiación estadounidense del panamericanismo. Sus objetivos estaban fundamentados en la promoción de la paz, del comercio y la amistad entre las repúblicas del continente

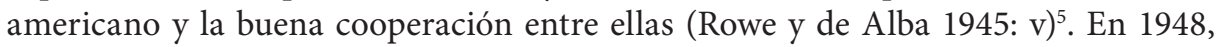
dicho organismo fue convertido en la Organization of American States (OAS) y no es de extrañar que, en el contexto de la posguerra, se hayan sumado a los objetivos iniciales la defensa de la soberanía, la integridad territorial y la independencia de los países miembros. La Colección Panamericana es producto de su tiempo, un tiempo de redefinición de las identidades en el hemisferio en la que americanismo y panamericanismo son centrales a la vez que mutuamente excluyentes.

\section{Anatomía de la Colección Panamericana}

La Colección Panamericana se publicó por primera vez en 1945 en Buenos Aires y tuvo una segunda y tercera edición en 1946 y en 1957; contó con un total de treinta y dos volúmenes de factura clásica (empastados en piel en formato de 14 por $20 \mathrm{~cm}$ ), los cuales no podían adquirirse individualmente, sino en conjunto. Un anuncio ${ }^{6}$, en 1947, de esta colección en la Revista de la Universidad de México confirma que se vendía a plazos: «Sólo \$ 20 de enganche y abonos mensuales de \$25». El anuncio incluye también una imagen del mueble (aquel mueble aludido por Reyes) que se adquiría para contenerla, con lo cual queda claro el valor otorgado a su dimensión de objeto. En el periódico Le Droit (Quebec) encontramos más datos sobre esta colección en una breve reseña publicada en 1946 sobre el volumen de literatura canadiense incluido en ella. Dicha reseña indica que el costo total de la colección era de 350 pesos (suponemos que se refiere a pesos argentinos, pues el contenido del texto indica la estancia del autor en Argentina), un precio justo, según él, dada la calidad de la edición y la relevancia de las obras reunidas (Dagenais 1946: 2) ${ }^{8}$.

Como no es de extrañar dado el apego de la casa Jackson a las prácticas enciclopédicas, los volúmenes están numerados según el orden alfabético del país al que representan, desde Argentina hasta Venezuela. Estos dos países, junto con Brasil, Colombia, Chile, Estados Unidos, México, Perú y Uruguay, tienen la particularidad de contar con dos volúmenes respectivamente. El resto, es decir, Bolivia, Canadá, Costa Rica, Cuba, Ecuador, Salvador, Guatemala, Haití, Honduras, Nicaragua, Panamá, Paraguay, Puerto Rico y República Dominicana, cuentan con uno solo. El contenido y la composición de los volúmenes son eclécticos: lo literario (Poe y Faulkner, por ejemplo, en el caso de Estados Unidos) convive con lo histórico y lo político (Sarmiento en el caso de Argentina y Martí en el de Cuba). Se entiende que aquí la etiqueta de «clásicos» se aplica a una gran variedad de producciones escritas que van de la novela al discurso político, pasando por el cuento, la poesía o el ensayo histórico. El género importa poco, en tanto que los textos presentados son «auténticamente americanos», pues según lo indica el breve «Propósito» firmado «Los editores» que abre cada volumen: «Ésta es, pues, una Colección de clásicos americanos. La palabra posee aquí una vigencia plena: son nuestros clásicos en cuanto son la expresión genuina de nuestros países» (Anòn. 1945: v). Esta declaración reivindica 
la legitimidad de la producción americana en su sentido más amplio, así como la independencia cultural de la región, punto de partida de todas las reseñas culturales incluidas en la colección. Los anónimos editores continúan no sin cierto lirismo su oda a un panamericanismo autodeclarado:

América posee constructores intelectuales como Hostos o Rodó, héroes como Bolívar o Martí, hombres de intensísima acción política como Sarmiento o Montalvo, artistas como Poe o Darío, sabios como Cuervo, que han dejado en páginas inmortales lo mejor de sí mismos. Esas páginas son estas que hoy ofrecemos. En cada país hemos elegido a quien mejor lo expresa, sea en su paisaje, sus hombres, su historia o su pensamiento. Y de cada uno de ellos su obra más cabal. (Anòn. 1945: v)

Esta colección de clásicos americanos destinados al mercado hispánico presupone, por lo tanto, y pone en juego, como sucede en todos los proyectos editoriales de este tipo, una construcción observable en una serie de procedimientos de selección, evaluación y reclasificación, donde la traducción ha de ser considerada (Seruya, D’hulst et al. 2013). En la mayoría de las portadas de la colección se atribuyen dichas operaciones a algún intelectual de renombre proveniente del país al que el tomo está dedicado. No siempre, sin embargo, la selección corre a cargo del autor de la «Reseña Cultural». En el caso de México, por ejemplo, Antonio Castro Leal firma la reseña, pero se atribuye a Alfonso Reyes la selección de los textos. Algo similar ocurre en uno de los tomos de literatura estadounidense, en donde Herschel Brickel firma la reseña cultural y la selección es producto de la colaboración del mismo Brickel, Dudley Poore y Harry R. Warfel. Al margen de estos detalles, es preciso subrayar que el énfasis que se pone tanto en el «Propósito» de la colección como en el anuncio antes citado, a la colaboración de los especialistas de cada país puede verse como una estrategia para legitimar el proyecto. No es de extrañar que esta misma estrategia vuelva a presentarse en las otras colecciones de Jackson, en donde en una portadilla se suele resumir la lista de ilustres colaboradores ${ }^{9}$, en lo que parece un intento de mostrar prestigio por asociación por parte del editor, prestigio que, como demuestra la actitud de Reyes, distaba de ser recíproco.

Subrayar, como se hace en el anuncio antes citado, que la selección y presentación de las obras provenía de «uno de los más destacados literatos del país al que la reseña se refiere» (W. M. Jackson Editores 1947: 9) sin duda contribuía a la legitimidad de la colección, pero también proyectaba la imagen de una política editorial que permitía que todas las repúblicas del Nuevo Mundo se autorrepresentaran. No obstante, el caso canadiense muestra algo diferente, pues su doble «Reseña Cultural» fue escrita desde Estados Unidos por Marine Leland y Herbert Davis. La primera era hija de padres estadounidenses nacida en Quebec y radicada en Estados Unidos, y el segundo, académico británico también radicado en Estados Unidos; ambos trabajaban en el Smith College de Massachusetts y, si bien eran especialistas de la cultura canadiense, difícilmente podrían considerarse como «hijos de más claro prestigio» (Anòn. 1945: vi) de dicho país. De hecho, el artículo de André Dagenais al que ya hemos aludido en lo relativo al costo de la colección, revela que la elección de Marine Leland para introducir la cultura francocanadiense dio lugar a críticas:

Pourquoi la Maison Jackson, qui a demandé à des écrivains de chaque pays l'introduction convenable, a-t-elle fait exception pour le Canada français? A Buenos Aires, on regrette ce fait. C'est New-York qui a décidé. Et une dame nord-américaine s'est crue capable de remplacer un écrivain de chez nous. C'est malheureux. (Dagenais 1946: 2) 
Como lo puntualiza Dagenais, las oficinas centrales de W. M. Jackson estaban en Nueva York y, aunque contara con sucursales en varios países, éstas actuaban con relativa independencia. Si bien la colección se imprimió en Buenos Aires y buscó la colaboración de intelectuales de toda la región, algunas decisiones se tomaban de manera central y unilateral desde Estados Unidos ${ }^{10}$.

El caso antes citado se suma a los otros indicios de que para W. M. Jackson, al igual que ocurre con el uso del discurso panamericano, contratar a intelectuales de cada país para escribir su respectiva reseña cultural, fue una estrategia de ventas antes que un compromiso intelectual. De hecho, el caso canadiense expone que el afán incluyente y representativo no está exento de acomodamientos asimétricos al no ser considerado Canadá como público o interlocutor principal de este proyecto. André Dagenais señala que W. M. Jackson habría acudido a las embajadas y los consulados del continente para comercializar la colección y supone que en Canadá sería adquirida por asociaciones como la Liga Panamericana de Canadá y la Unión de Latinos; también sugiere su valor potencial para los estudiantes de español, lo cual confirma la limitada red de destinatarios de la colección en dicho país.

En el «Propósito» de la colección se reivindica la unidad entre los países de toda América. En este sentido las reseñas intentarán trazar la historia de estos países, proceso mediante el que, de acuerdo con los editores, se evidenciará el pasado común de este conjunto. Cada una de ellas trazará los inicios de la cultura americana a partir de la llegada de los colonizadores europeos, señalando, sin falta, el momento de transición entre la imitación de los modelos europeos y el desarrollo de una cultura independiente en cada uno de estos países. Del mismo modo, las obras seleccionadas mostrarán la cultura de cada país y su inserción en este repertorio permitirá sacar a la luz cierta singularidad panamericana. De este modo, la colección construye la realidad panamericana que la sostiene.

\section{Construir la realidad panamericana: reseñas culturales, traductores y traducciones}

\subsection{Asimetrías en la representación de las culturas traducidas}

Hemos establecido hasta ahora que, si bien el proyecto panamericano de la editorial Jackson declaró su afán representativo, en la práctica esto muchas veces se quedó en el plano discursivo, lo cual se puede apreciar con mayor claridad en la selección y presentación de obras traducidas. En la forma en que se introduce a Brasil, Canadá, Estados Unidos y Haití se advierte, por un lado, que cada uno de estos países tiene un peso distinto y, por otro, que lo que se representa -una realidad económica, lingüística, cultural- puede diferir sustancialmente.

Hay una diferencia inicial porque Brasil y Estados Unidos aparecen con dos volúmenes en la colección, mientras que Canadá y Haití sólo con uno, lo cual bien podría deberse a la relevancia y el peso demográfico de estos países en la región. Si a eso sumamos el hecho de que esta colección, si bien publicada en español desde Argentina, es un producto estadounidense, se entienden mejor los datos contenidos en la siguiente tabla: 
CUADRO 1

Número de volúmenes por país

\begin{tabular}{|l|c|c|}
\hline \multicolumn{1}{|c|}{ País } & Volúmenes & Autores representados \\
\hline Brasil & 2 & 2 \\
\hline Canadá & 1 & 2 \\
\hline Haití & 1 & 1 \\
\hline Estados Unidos & 2 & 27 \\
\hline
\end{tabular}

Vayamos a los detalles. En el primer volumen dedicado a Brasil tenemos una «Reseña Cultural» a cargo de Afranio Peixoto y la obra Los Sertones (1902) de Euclides da Cunha, traducida por Benjamín de Garay; en el segundo, un «Prólogo» sobre la vida y obra de Machado de Assis redactado por Lucia Miguel Pereira, seguido de la novela Dom Casmurro (1899) y tres cuentos de dicho autor, traducidos por J. Natalicio González. En el caso de Estados Unidos, el primer volumen titulado Cuentistas Norteamericanos (que cubre un periodo que va de 1819 a 1943) incluye una «Reseña Cultural» escrita por Herschel Brickel que presenta una antología de 27 cuentos de autores distintos ${ }^{11}$, de quienes, además, se incluye una breve biografía. Las traducciones corrieron a cargo de J. R. Wilcock (11 cuentos), Nina Maganov (4 cuentos), J. L. Izquierdo (3 cuentos), Marta Vidal Bustos (3 cuentos), María Lía Marquardt de Álvarez (2 cuentos), Carmen Torres Calderón de Pinillos (2 cuentos), Graciela del Campo y Plata (1 cuento) y Alberto Gutiérrez Castro (1 cuento). Dos de dichas traducciones fueron recuperadas de publicaciones anteriores y 25 encargadas por la editorial Jackson. Las dos traducciones recuperadas, Rip Van Winkle de Washington Irving y La caída de la casa de Usher de Poe, fueron publicadas originalmente en 1920. Ambas están firmadas por Carmen Torres Calderón de Pinillos y aparecieron en dos volúmenes de cuentos de la Biblioteca Interamericana, fundada por la Dotación Carnegie para la Paz Internacional con el objetivo de fomentar «la difusión de ideas entre los pueblos del Nuevo Mundo, mediante la traducción y publicación de obras importantes que expresen los ideales y los sentimientos nacionales» ${ }^{12}$. El segundo volumen, que cuenta con un prólogo de Muna Lee de Muñoz Marín, está consagrado a la obra de Nathaniel Hawthorne, autor también presente en la antología antes mencionada, y que en este volumen aparece con su novela The Scarlet Letter (1850) y cinco cuentos más, en traducción de Fernando Baeza Martos. En lo que toca a Canadá y Haití, no se observa una exposición tan dilatada de su producción escrita. Canadá, el caso más sobresaliente en lo que toca a las estrategias de compresión, figura con el volumen titulado Dos culturas canadienses, que ofrece dos reseñas culturales, una de la cultura francocanadiense y otra de la anglocanadiense, respectivamente a cargo de Marine Leland y Herbert Davis, seguidas de Les Anciens Canadiens (1863) de Phillippe [sic] Aubert de Gaspé, traducida por J. L. Izquierdo, y The Clockmaker (1836) de Thomas Chandler Haliburton, en traducción de Alberto Gutiérrez Castro. Cabe mencionar que ambas obras sufrieron considerables recortes en la edición de Jackson. Por último, tenemos a Haití con un volumen que consta de una «Reseña Cultural» escrita por Pierre Moraviah-Morpeau y la novela Séna (1905) de Fernand Hibbert, traducida por Juan Paredes. No es nuestra intención detenernos demasiado en estos datos, pero son relevantes porque enmarcan la inserción asimétrica de estos países a esa cultura panamericana que en el «Propósito» de los editores se expone de manera muy igualitaria. 
Siguiendo el hilo de la representación asimétrica en la colección, no podemos dejar de mencionar que, si bien la inserción de los textos de Brasil, Canadá y Haití se justifica en sus respectivos prólogos debido a su capacidad para representar realidades nacionales concretas, en el caso estadounidense lo que está en juego no es la representación de una identidad, dada por sentada, sino la de un género literario, el cuento. El volumen Cuentistas Norteamericanos en la Panamericana es variado en todo sentido. Se presenta una amplia gama de autores y periodos: desde escritores clásicos del siglo XIX como Nathaniel Hawthorne, Washington Irving y Edgar Allan Poe hasta autores del siglo XX como William Faulkner y Ernest Hemingway; pero, además, este es el único volumen de la colección que presenta textos escritos por mujeres, con una nómina que incluye a autoras como Katherine Anne Porter, Eudora Welty y Kay Boyle, lo cual no es casual, pues se afirma en la reseña cultural que «Nunca han faltado las mujeres en la lista de nuestros cuentistas famosos» (Brickel 1945: xxviii). Es de notar también que la «Reseña Cultural» de Estados Unidos es la única dentro de la Colección Panamericana que no se centra en la realidad geográfica, histórica, política, lingüística y cultural de su país, lo cual sí ocurre con el resto; es en todo rigor una historia del desarrollo del cuento en Estados Unidos. Esta reseña parte de una posición distinta ya que presupone un conocimiento general de la cultura estadounidense y va en una dirección contraria a la síntesis que rige al resto de los volúmenes.

Se ha visto que el panamericanismo de la colección de la que aquí nos ocupamos implicaba la inclusión de países que, por su lengua o por su situación en la geografía del continente, eran referencias distantes al mundo hispanoamericano. En este sentido, la representación de Haití y Canadá en la colección pone de manifiesto las formas muy diversas en las que los países acceden al repertorio panamericano. Haití cuenta con una «Reseña Cultural» claramente enfocada en situar este territorio desconocido en el continente. Ofrece una gran cantidad de datos sobre el clima, la flora, la fauna, e incluso las coordenadas del país:

La isla de Santo Domingo está situada de Sur a Norte entre los $80^{\circ} 01$ y $20^{\circ} 06$ de latitud septentrional. Del Este al Oeste, entre los $71^{\circ} 38$ y $74^{\circ} 29$ long. occidental, partiendo del meridiano de Greenwich. (Moraviah-Morpeau 1945: viii)

Pierre Moraviah-Morpeau, autor de la reseña, se identifica como un ferviente adepto del panamericanismo al declarar haber pronunciado « 426 discursos por radio para celebrar y recordar a todas las naciones de América...» y haber «...traducido al francés todos los himnos nacionales de las distintas naciones americanas para que los hijos de Haití penetren más en el alma de sus hermanos continentales» (MoraviahMorpeau 1945: xviii-xix). El exacerbado entusiasmo de este reseñista en cuanto a la participación de Haití en el diálogo continental por medio de la colección contrasta con el tono más objetivo y distanciado del resto de las reseñas. En cuanto a la obra seleccionada, ésta se sitúa, como lo indica Fleischmann (1983: 73), entre la producción de autores haitianos que imitan a los autores franceses decimonónicos, a Balzac ${ }^{13}$ en particular, y que promueven una visión idealizada de la vida política haitiana, mediante una exposición un tanto ingenua y llana. Al contrario, en el caso del Canadá francés, la reseñista Marine Leland insiste en la necesidad de reconocer el desarrollo singular de la literatura francocanadiense, calificando de absurdas las comparaciones con los modelos europeos en general y franceses en particular, una postura en el 
extremo opuesto a la deferencia de Moraviah-Morpeau frente a la cultura francesa. La prioridad de mostrar la singularidad cultural francocanadiense lleva a la selección de lo que «ni siquiera podría calificarse de una buena novela» (Leland 1946: xxii). Acaso esta distancia crítica que contrasta con la militancia de Moraviah-Morpeau, se deba al hecho ya señalado de que la mirada de Leland es más que nada una mirada externa, desde los Estados Unidos, una mirada enfocada al caso de Canadá y de su biculturalismo. La reseña de Brasil, en cambio, muestra el desarrollo de la literatura brasileña a lo largo de la historia del país, pero inscribiéndola siempre en el marco del continente americano. Esto se advierte desde las primeras líneas donde no se parte de lo específicamente brasileño, sino del continente en general:

Es evidente que en los días del descubrimiento de América no podía haber una literatura, concentrados como estaban los esfuerzos en la posesión del continente y la erección de las primeras poblaciones, empresa que demandó muchas décadas, tanto en la América española como en la inglesa y en la portuguesa. (Peixoto 1945: vii)

Quizás esta preocupación por lo continental en la reseña sea un eco de aquella soledad en la que se encontraba Brasil antes de estos años y a la que ya hemos aludido anteriormente. A pesar de las evidentes asimetrías en cuanto a lo que muestran las reseñas culturales, en lo que concierne a las traducciones, se advierte, como se mostrará a continuación, una tendencia homogeneizante que corresponde al constructo de una lengua neutra.

\subsection{Traducir para todos al español de nadie}

Para hablar de la traducción de los textos antes mencionados, hemos de volver a las Instrucciones a sus traductores y correctores que citamos en la introducción. W. M. Jackson contaba con un manual de estilo concebido para esta y el resto de sus publicaciones, en donde la principal consigna era asegurar que el lenguaje fuera comprensible por la totalidad del público hispanoamericano, lo cual para los asesores literarios que firman dichas instrucciones, implicaba la adopción de una lengua exenta de influencias externas (anglicismos, galicismos, italianismos y portuguesismos) y libre de variantes regionales (rioplatensismos y aragonismos, por citar dos ejemplos que se dan en el manual), conforme a un estándar peninsular que incide en usos gramaticales poco comunes en la región (principalmente el vosotros y el futuro simple). El afán por promover el uso de un español al alcance de todos se extiende a la búsqueda de una lengua sin vulgarismos ni cultismos. Las listas a las que da lugar esta misión dejan al lector estupefacto por su carácter un tanto surrealista: se propone sustituir jeep por yip (plural, yipes), pic-nic [sic] por excursión o merienda campestres, pequeña mesa por mesita, pequeño perro por perrito, pizza por cierta empanada grande $y$ plana... Si bien dichas listas contienen palabras o frases de lenguas europeas, el manual no desaprovecha la oportunidad de advertir sobre otro tipo de influencias indeseables:

Asimismo hemos prescindido de barbarismos originarios de idiomas que han tenido poca influencia sobre el nuestro aunque podríamos poner en la picota [el énfasis es nuestro] vocablos procedentes de los idiomas amerindios, de los negroafricanos, de los eslavos, del alemán, etc. (Náñez e Izquierdo 1945: 21) 
En un tono menos violento, pero manteniendo el ideal de una lengua pura en sus orígenes, concluye el manual con una admonición marcadamente esencialista, que fija y limpia la lengua española, salvándola de los desvíos a los que ha dado lugar su presencia en América. Después de lamentar el cambio en la significación de la palabra saco de insigne herencia (sánscrito, griego y latín), y su adopción en América con el sentido de chaqueta, cierran los autores con el siguiente llamado: «Todo lo expuesto indica la conveniencia de usar las palabras en sus acepciones primarias, y sustituir las menos correctas por otros vocablos castizos, habituales en los veintiún países que hablan nuestro idioma» (Náñez e Izquierdo 1945: 32).

Estas instrucciones, si bien grotescas, parten de la creencia en un español total, panhispánico, capaz de sobreponerse a los vacíos de sentido que supondría el uso de variantes regionales. Sin embargo, cabe señalar que la tendencia a ocultar los regionalismos es un fenómeno generalizado que ha sido objeto de estudio y que de hecho sigue incidiendo en las políticas editoriales y de traducción en el mundo hispánico (Falcón 2011). Son conocidos los debates que tuvieron lugar en Argentina en los años 20 en torno a la lengua nacional (Lida 2012), y reconocido el triunfo en la década de los cuarenta de «una ideología lingüística "universalista” y elitista» (Falcón 2011: 115) en el contexto del protagonismo de Argentina en la industria editorial de la época. Por lo tanto, en el caso de Jackson, quien publica su colección en Argentina, no es de sorprender que la lengua que se ofrece como solución al problema de la inteligibilidad sea una lengua con rasgos principalmente peninsulares. En ese sentido, siguiendo la lógica de los redactores de estas instrucciones, los usos de construcciones españolas del siglo de oro (pues algunas de las citas que usan como ejemplos son de dicho periodo) se consideran deseables porque representan el uso correcto de la lengua, no obstante su anacronismo. Esta visión prescriptiva y estática del español, de hecho se traslada a las traducciones como lo indican los ejemplos que exponemos a continuación.

La mera existencia de dichas Instrucciones nos obliga a considerar el perfil de los traductores que trabajaban para Jackson; nada indica que fueran letrados-traductores, en el sentido que le da a esta fórmula Patricia Willson (2008), o sea figuras de legitimidad intelectual y política, conocedoras e importadoras de obras extranjeras. Más bien, en su mayoría, los traductores de la Panamericana no parecen haberse desempeñado en el mundo intelectual de su época más allá de las varias colecciones de Jackson o de otros proyectos editoriales que en aquella época del boom editorial argentino requerían traductores. Este es el caso de figuras como Graciela del Campo y Plata, José Luis Izquierdo, Alberto Gutiérrez Castro, Nina Maganov, María Lía Marquardt de Álvarez y Marta Vidal Bustos de quienes no encontramos datos biógraficos fuera de su labor traductora en dichos proyectos. Son escasas las figuras de mayor alcance: J.R. Wilcock, traductor y escritor argentino, cercano al grupo de la revista Sur; Fernando Baeza Martos, diplomático español que vivió en México y en Argentina; Juan Natalicio González Paredes, figura importante de la política y de las letras paraguayas, cuya labor como traductor, no obstante, es desconocida. De hecho, puede que él mismo o la propia editorial haya decidido atenuar su visibilidad: si bien firmó con el nombre J. Natalicio González la reseña cultural del volumen de Paraguay y la traducción de Don Casmurro del segundo volumen de Brasil, puede que haya elegido el seudónimo de Juan Paredes, una versión abreviada de su nombre, para firmar sus traducciones del francés (Sena, para la Panamericana y varias obras de Flaubert par otras colecciones de Jackson). 
Antes de mirar con mayor detenimiento las traducciones para identificar los efectos de las recomendaciones contenidas en el manual en el discurso identitario, es preciso mencionar que dos de los traductores cuyo trabajo se incluye en la Colección Panamericana no fueron contratados por Jackson ya que sus traducciones se habían publicado anteriormente: este es el caso de Benjamín de Garay, traductor de Los Sertones y de Carmen Torres Calderón de Pinillos, traductora de Washington Irving y de Edgar Allan Poe. El caso de Benjamín de Garay, traductor argentino y reconocido introductor en su país de la brasilidad (Sorá 2003: 115) merece ser subrayado pues contrastan con la neutralidad asumida de los demás traductores de Jackson tanto su perfil de mediador cultural como su postura de traductor comprometido con dar a conocer las realidades de Brasil expresadas en su literatura.

Si bien el uso de un español más bien peninsular constituyó una norma de traducción en América por esos años, el caso de la Panamericana muestra que la aplicación de esta norma no implicaba el rechazo de cierto heterolinguismo en las obras traducidas, siempre y cuando la otredad lingüística no procediera del mundo hispánico. En cierta medida, el caso aquí presentado constituiría una de las tantas respuestas a la pregunta formulada por Patricia Willson sobre las prácticas de traducción en Argentina a finales de los años 1930 y principios de los 1940:

¿En qué condiciones y negociando qué cosas se privilegia en las traducciones la norma peninsular o la rioplatense, entre otras posibles variantes de América Latina, o se privilegia un 'compósitum' sin lugar de anclaje, el llamado 'español neutro'? (Willson 2011:152)

El estudio de las traducciones en la Colección Panamericana puede ofrecer pistas para entender mejor este fenómeno. Todo indica que, al menos en lo que a la editorial Jackson se refiere, la búsqueda del español neutro se defiende con el argumento de la inteligibilidad y, ya sea que se deba al posible origen español de los redactores del manual de estilo de W. M. Jackson o a una práctica común en la época, la tendencia a privilegiar el español peninsular que se advierte en la Colección Panamericana, es todo excepto neutra, pues devuelve la carga colonial a un proyecto que supuestamente reivindica la independencia cultural americana. Si bien esto plantea una gran contradicción al interior de esta colección, en el contexto editorial más amplio, refleja la asunción del español peninsular como modelo de lengua culta. A pesar de que el traslado de las actividades editoriales desde España hasta América podría haber supuesto un cambio de régimen en cuanto a la lengua de traducción, Alejandrina Falcón concluye desde el enclave argentino que

la centralidad editorial de la Argentina coincidió con el triunfo de una ideología lingüística 'universalista' y elitista a un mismo tiempo; y apuntaló a escala hispanoamericana la creencia -aún vigente en lo relativo a la lengua de traducción- según la cual los rasgos regionales marcados deben quedar excluidos de los soportes impresos destinados a circular en un mercado internacional (Falcón 2011:115).

El caso de la Panamericana confirma la vigencia, en esta época, del meridiano europeo y, a pesar de las diferencias observables en la retórica de los paratextos, la traducción privilegia usos de la lengua que son exclusivos de España y cuya manifestación más clara es el uso del vosotros. Otro rasgo sobresaliente son los giros marcadamente arcaicos. Desde las primeras páginas del volumen canadiense, se advierten dichas características: «Verdaderamente, respondíle, me hacéis un honor, 
pues veo, por esta vuestra acogida, que soy la excepción, el hombre que esperabais para...» (Aubert de Gaspé 1863/1946: 2).

En el caso de Sena las estrategias son similares y el uso del vosotros se combina con el empleo de modismos peninsulares: «No me habléis de ella -les respondió-, es un "paquete"» (Hibbert 1902/1945: 138). Es significativo que la traducción al español de Sena publicada por Jackson en su colección, reeditada en 1977 por la editorial cubana Casa de las Américas, tuviera que pasar por una revisión (llevada a cabo por Roberto Romaní Velazco) que consistió esencialmente en la eliminación de las conjugaciones peninsulares y el cambio de algunos usos léxicos. De este modo, el pasaje anteriormente citado se lee en esta edición cubana: «No me hablen de ella -les respondió-, es insoportable» (Hibbert 1902/1977: 134).

No sorprende la adaptación de la traducción de Sena dentro del marco de la recuperación de la literatura antillana (una literatura minoritaria y como tal muy poco traducida) que en los años sesenta empezó a promoverse en Cuba. ${ }^{14}$ En el caso de Los antiguos canadienses, el hecho de que la traducción de Jackson haya sido la única al español y que no haya sido reeditada por otra editorial, puede sorprender dado el carácter fundacional de esta obra en la historia de la literatura francocanadiense. Sin embargo, dos factores bien podrían haber influido en este hecho: por un lado, la lejanía, hasta años recientes, de la cultura francocanadiense respecto de las preocupaciones y debates culturales e identitarios hispanoamericanos. Por otro lado, las propias características de esta traducción que somete al texto de partida a recortes significativos pues sin ninguna advertencia se omiten tanto frases y párrafos como capítulos enteros.

\subsection{Brasil, un referente obligado}

Si bien, en aquella época, Canadá y Haití no eran protagonistas de las discusiones en torno a la identidad americana, Brasil representaba en estas un elemento indispensable en la nueva configuración de la americanidad observada en la construcción de repertorios llevada a cabo en diversas colecciones. Por ejemplo, según los responsables de Tierra Firme, la inclusión de Brasil es fundamental para fomentar la comunicación y el diálogo continental, y dar fin a los «monólogos de los pueblos latinoamericanos» (Frontini citado en Sorá 2008: 561). En el caso de la Biblioteca Americana también se reconoce la importancia de Brasil, no obstante las dificultades que conlleva su inclusión, tales como establecer vínculos con intelectuales brasileños y conseguir traductores (Weinberg 2014).

Hacia 1945, año de la primera edición de la Colección Panamericana existían al menos dos traducciones de Los Sertones al español: la de Benjamín de Garay, como hemos dicho un traductor argentino que vertió mucha literatura brasileña al español en este contexto de aproximación a Brasil, y la del uruguayo Enrique Fabregat, publicada en México (Peixoto 1945: xxvi). Según añade el mismo Peixoto, autor de la «Reseña cultural» del primer tomo de Brasil, se tenía noticia de la segunda traducción, pero parece no haber circulado mucho fuera de México en esos años. La traducción que se reproduce en la Colección Panamericana es la de Benjamín de Garay. Cabe aclarar que esta traducción se había editado ya dos veces antes de su publicación por W. M. Jackson: la primera de ellas, en 1938, dirigida a un público culto, en la Biblioteca de autores brasileños traducidos al castellano, una iniciativa 
del régimen conservador mitrista interesado en estrechar los lazos entre Argentina y Brasil (Pasero 2004: 96); la segunda, de 1942, a cargo de la editorial Claridad en Buenos Aires destinada a un público más amplio. Estas dos ediciones tienen rasgos distintos, relevantes para los fines de este artículo. Como lo indica Pasero, se observa que Benjamín de Garay hizo cambios sustanciales a la edición de 1942, como la adición del subtítulo La tragedia del hombre derrotado por el medio, que no está en el original; un nuevo y más sustancioso prólogo del traductor y una mayor profusión de notas explicativas no eruditas sino más bien pedagógicas, referentes a las numerosas palabras mantenidas en portugués, estrategias que sin lugar a dudas acercan el texto a un público argentino.

No es de sorprender que, en vista de las Instrucciones a sus traductores... de Jackson y el tono de la Colección Panamericana, se haya reproducido la primera edición de esta traducción, la más neutra y conservadora. Jackson, con todo, impone sus propias restricciones a esta edición, omitiendo el prólogo «Dos palabras del traductor», en donde de Garay, explica, por ejemplo, su decisión de traducir el título mediante un calco del portugués, decisión que, por cierto, traductores posteriores han mantenido. Es en este último punto, la presencia del portugués en la traducción de de Garay, donde queremos detenernos, pues muestra cierta ambivalencia o quizás descuido por parte de Jackson y es una de las principales diferencias entre esta traducción y las que fueron hechas para la Colección Panamericana.

Se observa desde la portadilla del volumen de Jackson algo muy inusual dentro de la Colección: la aparición del título Los Sertones seguido del paréntesis ( Os Sertões»). Esta es la pauta que rige al texto donde hay una clara presencia de la lengua fuente, el portugués. No hace falta sino hojear el volumen para advertir la ingente cantidad de palabras en cursiva, punto de entrada de palabras portuguesas cuya incógnita no se resuelve en la página, pues su traducción se ofrece en un glosario denominado «Notas del traductor» incluido al final del volumen, una práctica habitual para Benjamín de Garay (Sorá 2003:115).

El glosario en sí mismo es un tema de interés, pues advertimos en varias entradas la presencia de la focalización argentina que no habría tenido cabida si esta traducción se hubiera producido siguiendo el manual de la casa Jackson. Es así que en la entrada de Capangueiro, tras una definición convencional que reza «En Bahía, en la zona diamantífera, llaman así a los compradores de lotes de diamantes, o piedras aisladas», se añade "[e]n rigor, la traducción de este brasileñismo sería pichinchero» (de Garay 1945: 523). Para citar otro ejemplo, en la definición de fazenda se dice: «Es el establecimiento rural en el Brasil. No es nuestra estancia, ni nuestra chacra, ni la granja o cortijo de los españoles» (de Garay 1945: 525). El punto de referencia en ambos casos es argentino y resulta notorio el uso del pronombre personal nuestro en un sentido excluyente (lo nuestro argentino en contraposición con lo brasileño o con lo español, por ejemplo). Un nuestro muy distante, por cierto, de ese nosotros incluyente movilizado por Jackson tanto en su construcción de la totalidad panamericana como en su defensa de la unidad de la lengua española.

A pesar de esta contradicción entre una postura argentina y los postulados de la casa Jackson con sus frecuentes referencias a los ciento veinte millones de hispanohablantes como un bloque homogéneo, la primera edición de la traducción de Benjamín de Garay que recuperó Jackson se adhiere a la principal estrategia de traducción de la casa en el sentido en que se homogeneiza el lenguaje en los diálogos, 
pues en ellos está presente el uso del vosotros peninsular. No obstante, esta traducción sobresale entre las otras en la Colección Panamericana al dar lugar a la heterogeneidad lingüística mediante la presencia de numerosas palabras en portugués y la aparición de los regionalismos argentinos en las definiciones del glosario. Es así como de manera inadvertida la lógica económica prevalente en la casa Jackson (al optar por una traducción existente) abre el camino a un tipo de representación no del todo conforme con sus Instrucciones.

\subsection{De la fazenda brasileña al cortijo español: traducir un cuento estadounidense de un español a otro}

Vimos que, en la traducción de Los Sertones, a pesar de la presencia de la norma peninsular, se permitía en el texto la entrada de la lengua portuguesa y en el glosario la de los argentinismos. Esta convivencia de lenguas queda fuera de la traducción à la Jackson, y por ello hemos elegido el cuento de Katherine-Anne Porter, María Concepción, incluido en el volumen Cuentistas Norteamericanos, que en su versión original introduce varias palabras en español sin ofrecer definiciones a pie de página ni advertencias sobre la heterogeneidad lingüística mediante el uso de cursiva. La historia se desarrolla en México y la inserción del español es un recurso estilístico primordial para esta narración. Algunos críticos han asociado el uso de los mexicanismos en la obra de Porter como muestra de su adscripción al realismo social (Walsh 1992: 74). ¿Qué efecto se produce cuando, como ocurre con la traducción que ofrece la Colección Panamericana, se borran todos los mexicanismos del cuento con el pretexto de la lengua neutra que busca garantizar la comprensión por parte de todos los hispanohablantes?

El título del cuento revela inmediatamente la presencia del referente no anglófono y no hay más que leer las primeras líneas para encontrar en la descripción de la protagonista las pistas que indican que la historia se desarrolla en otra cultura. Cuando en la descripción encontramos la frase «Her straight back outlined itself strongly under her clean blue cotton rebozo» (Porter 1922: 224) el uso de la palabra rebozo no sólo designa una prenda de vestir, sino que introduce otra realidad cultural y lingüística. Esa doble función que se asigna a los mexicanismos en el cuento de Porter está escindida en la traducción de Alberto Gutiérrez Castro para la Colección Panamericana, en donde la misma frase aparece como «Su espalda recta se dibujaba nítidamente por el limpio algodón azul del manto» (1922/1945: 431). Lo mismo ocurre con el resto de los mexicanismos del cuento. Resulta interesante recordar la intervención del traductor de Los Sertones en la definición de la palabra portuguesa fazenda, pues la palabra equivalente en español, hacienda, aparece en este cuento: «But María Concepción was always as proud as if she owned a hacienda» (Porter 1922: 225), que en la traducción se vierte a «Pero María Concepción siempre fue tan orgullosa como si hubiera poseído un cortijo» (Porter 1922/1945: 433). ¿No dijo Benjamín de Garay (1945: 525) en su glosario para Los Sertones: «No es nuestra estancia, ni nuestra chacra, ni la granja o cortijo de los españoles»? Este es acaso uno de los puntos en que podemos ver con mayor claridad qué léxico privilegian los traductores de Jackson. Curiosamente, solo uno de los mexicanismos del cuento de Porter se conserva, pero no sin una advertencia del traductor. La frase «El agobiado jacal de juncos...» (Porter 1922/1945: 433) va acompañada de la nota a pie de página: «jacal: (del mejicano, xacalli). Choza. 
(Diccionario de la Real Academia Española)» (Gutiérrez Castro 1945: 433). La presencia de esta nota, ausente en el original, ejemplifica con gran nitidez el filtro por el que pasa la lengua de traducción en la Colección Panamericana. Cabe notar que la ortografía elegida para la palabra mejicano pone de manifiesto la lejanía del traductor respecto a este contexto y su adscripción a la norma peninsular. La referencia a la Real Academia Española en dicha nota remite además a un acto de regulación evocador del testimonio de un diputado argentino de 1938, recogido por Alejandrina Falcón: «España podría ofrecernos [...] valores capaces de ejercer en nuestro medio la función depuradora del idioma» (Falcón 2011: 115). Sin duda, muchos factores, tanto económicos como ideológicos, influyeron en el hecho de que en América el español peninsular mantuviera su poderío como lengua de traducción. Lo paradójico es que en un periodo incipiente de producción editorial latinoamericana a gran escala y de afirmación de la americanidad se consolidara dicha política.

\section{Conclusiones}

«Creemos, pues, aportar con esta Colección una fuerza más a las que trabajan por el leal entendimiento de los países del Nuevo Continente» (Anón. 1945: v-vi), indican los anónimos editores que firman el «Propósito» de la Panamericana. Sin embargo, lo que deja ver la disparidad en la presentación de los países traducidos, la selección de los textos y las propias estrategias de traducción, más conformes con una apuesta por un español supuestamente neutro que con las realidades culturales que estos textos dan a conocer, es que la materialización de dicho entendimiento es compleja y conlleva toda una serie de decisiones que en la práctica privilegian posturas hegemónicas ya sea económicas o lingüísticas. La Colección Panamericana es, pues, emblemática de su época: por una parte, ilustra una doctrina que expresa ante todo los intereses comerciales e ideológicos de Estados Unidos, país que en este contexto es meridiano de la americanidad. Por otra parte, es vehículo de un panhispanismo fundamentado en una lengua común, pero en el que España se mantiene como punto de referencia, a pesar de la distancia geográfica y de la profusión de discursos identitarios sobre la americanidad en muchos de los proyectos editoriales de la época. Cabe subrayar que, en la actualidad, si el discurso panamericanista parece haberse diluido, los debates en torno al panhispanismo continúan en el contexto cada día más complejo de la internacionalización de los bienes culturales y de su circulación. De la misma manera, la diversificación de los polos de irradiación de la lengua española (Lara 2007: 180) evidencia cada vez más su realidad pluricéntrica, una realidad que, lejos de entorpecer la comunicación, contribuye al entendimiento entre los países de esta amplia comunidad lingüística sin por ello contradecir la unidad de la lengua española. Si bien la consideración de la pluralidad lingüística en la traducción al español plantea retos difíciles de enfrentar, el caso aquí expuesto contribuye a ilustrar la centralidad de las prácticas traductoras en la recepción y propagación de las ideologías sobre la lengua. 


\section{NOTAS}

1. Nos referimos como ejemplo al propósito que abre Cuentistas Norteamericanos (Brickell, Poore et al. 1945).

2. En este trabajo nos referimos a esta editorial como W. M Jackson, Jackson o W. M. Jackson Inc., aunque a lo largo de los años e incluso dentro de un mismo volumen dicha empresa se viera reconocida bajo otras apelaciones como: Jackson Editores, Ediciones Jackson, Jackson o Editorial Jackson de Ediciones Selectas.

3. Fernández Moya, María (2008): El proceso de internacionalización del sector editorial español, no publicar. IX Congreso de la Asociación de Historia Económica, Murcia, 9-12 de septiembre de 2008. Consultado el 10 de junio de 2017, <http://www.aehe.es/wp-content/uploads/2008/09/ El-proceso-del-Sector-Editorial.pdf $>$.

4. En la portada de los dos tomos de México en la Colección Panamericana se da crédito a Alfonso Reyes por la selección de los textos.

5. Rowe, Leo Stanton y Alba, Pedro (de) (1945): The Pan American Union. In: Bulletin of the Pan American Union. Vol. 79. Washington, D. C.: Pan American Union, v.

6. W. M. Jackson Editores (1947): Colección Panamericana [Anuncio]. Revista de la Universidad de México. 1(9):9. Consultado el 30 de octubre de 2017, <http://www.revistadelauniversidad.unam. $\mathrm{mx} /$ historico/10064.pdf $>$.

7. Estas cifras se vuelven significativas si se comparan con el precio de los volúmenes individuales de otras colecciones de esta época: entre 3 y 8 pesos para Escritores Mexicanos (Editorial Porrúa) y entre 6 y 12 pesos para Tierra Firme (FCE), según los anuncios publicados en la misma revista. A esta diferencia en el precio, se suma la imposición, en el caso de Jackson, de comprometerse a adquirir la colección completa.

8. Dagenais, André (1946): Une édition espagnole des Anciens Canadiens. Le Droit. 34(233):2.

9. Esto ocurre, por ejemplo, en la colección Clásicos Jackson, donde la página que contiene los «Títulos de que se compone esta serie» es precedida por otra que reza «Clásicos Jackson publicados con la colaboración y estudios preliminares de los siguientes ilustres escritores de España y América». Se incluye un listado con los nombres de dichos escritores y sus méritos académicos. Por ejemplo: «Jorge Luis Borges: escritor, crítico y erudito argentino, de extensa y calificada producción poética y novelística. [...] Alfonso Reyes: Miembro de la Real Academia Española, de la Academia Argentina de Letras y de la Junta de Historia y Numismática Americana. [...] Guillermo de Torre: poeta, crítico y ensayista español residente en la Argentina». Ambas páginas constituyen la primera información ofrecida al lector, pues aparecen antes que el título y la portada del volumen en cuestión.

10. También es de señalar el papel central de Nueva York en cuanto a la circulación de los libros en América latina, incluso en proyectos editoriales no relacionados con Estados Unidos. Como lo señala Daniel Cosío Villegas (1947/1985: 7), «[...] los libros que se despachan desde México para todos los países latinoamericanos, van primero a Nueva York para ser transportados desde allí en barcos norteamericanos.»

11. Siguiendo el orden de aparición en la antología: Washington Irving, Nathaniel Hawthorne, Edgar Alan Poe, Rose Terry Cooke, Fitz-James O’Brien, Francis Bret Harte, Frank R. Stockton, Samuel Langhorne Clemens (Mark Twain), Ambrose Bierce, Henry James, Sarah Orne Jewett, William Sidney Porter (O. Henry), Edith Warton, Stephen Crane, Jack London, Sherwood Anderson, Irvin S. Cobb, Willa Cather, Wilbur Daniel Steele, Dorothy Parker, Katherine Anne Porter, William Faulkner, Stephen Vincent Benet, Ernest Hemingway, John Steinbeck, Kay Boyle y Eudora Welty.

12. (Cuentos Clásicos del Norte 1920: Iv)

13. De hecho Moraviah-Morpeau (1945: xliv) considera a Hibbert «El Balzac de Hatí», una observación corroborada por el título de otras de sus novelas: Scènes de la vie haïtienne. Les Thazar (1907) y Scènes de la vie haïtienne. Romulus (1908).

14. Arencibia, Lourdes (26 de mayo de 2009): Medio siglo de traducción y edición de las literaturas anglo y franco caribeñas en Cuba. Cuba literaria. Consultado el 4 de junio de 2017, <http:// www.cubaliteraria.cu/articulo.php?idarticulo $=8095 \&$ idseccion $=55>$.

\section{REFERENCIAS BIBLIOGRÁFICAS}

ArdaO, Arturo (1993): Panamericanismo y Latinoamericanismo. In: Leopoldo ZEA, ed. América Latina en sus ideas. México: Siglo xxi Editores-Unesco, 157-171. 
Cosío Villegas, Daniel (1947/1985): La industria editorial y la cultura. In: Gabriel Zaid, ed. Daniel Cosío Villegas. Imprenta y Vida Pública. México: FCE, 1-26.

Cosío Villegas, Daniel (1949): España contra América en la industria editorial. Sur. 17(174):7488.

De Diego, José Luis (2006): Editores y Políticas Editoriales en Argentina,1880-2000. Buenos Aires: Fondo de Cultura Económica.

Del Valle, José (2007): La lengua ¿patria común? Ideas e ideologías del español. Madrid: Vervuert/Iberoamericana.

Díaz, José Simón (1950): Bibliografía de la literatura hispánica. Vol. 1. 3ª ed. Madrid: Instituto Miguel de Cervantes.

Falcón, Alejandrina (2011): ¿Un meridiano que fue exilio? Presencia española en el campo cultural argentino (1938-1953). In: Andrea PAGNI, ed. El exilio republicano español en México y Argentina. Historia cultural, instituciones literarias, medios. Madrid: Iberoamericana/ Vervuert.

FERnÁndeZ, Pura (1998): El monopolio del mercado internacional de impresos en castellano en el siglo XIX: Francia, España y la 'ruta' de Hispanoamérica. Bulletin hispanique. 100(1):165190.

Fleischmann, Ulrich (1983): Para una aproximación sociológica a la literatura haitiana. Revista de Crítica Literaria Latinoamericana. 9(17):65-87.

Hallewell, Laurence (1982/2005): O Livro No Brasil: Sua Historia [El libro en Brasil: su historia]. (Traducido del inglés por María da Penha Villalobos, Lólio Lourenço de Oliveira y Geraldo Gerzon De Souza) 2a ed trad. São Paulo: EDUSP.

LARA, Luis Fernando (2007): Por una reconstrucción de la idea de la lengua española. In: José DEL VAlle. La lengua, ¿patria común? Ideas e ideologías del español. Madrid/Frankfurt: Vervuert/Iberoamericana, 163-195.

Lehman-Haupt, Hellmut (1939): The Book in America: A History of the making, the selling and the collecting of books in the United States. New York: R. R. Bowker.

LIDA, Miranda (2012): Una lengua nacional aluvial para la Argentina. Prismas. 16:99-119.

NÁÑEZ, Demetrio e IzQuierdo, José Luis (1945): Instrucciones a sus traductores y correctores. Buenos Aires: W. M. Jackson.

PARK, Stephen M. (2014): The Pan American Imagination: Contested Visions of the Hemisphere in Twentieth-Century Literature. Charlottesville: University of Virginia Press.

PARK, Stephen M. (2017): Sites of Pan-American thinking: a methodology of place. In: Wilfried RAussert, ed. The Routledge Companion to Inter-American Studies. Londres/New York: Routledge.

Pasero, Carlos A. (2004): Los límites de la lengua. Benjamín de Garay y la praxis de la traducción. Revista da Pós-Graduação en Letras - UFPB João Pessoa. 6(2/1):95-100.

Seruya, Teresa, D'hulst, Lieven, Assis Rosa, Alexandra et al. (2003): Translation in Anthologies and Collections (19th and 20th Centuries). Ámsterdam/Filadelfia: John Benjamins.

Sorá, Gustavo (2003): Traducir el Brasil. Una antropología de la circulación internacional de las ideas. Buenos Aires: Libros del Zorzal.

SorÁ, Gustavo (2008): Misión de la edición para una cultura en crisis. El Fondo de Cultura Económica y el americanismo en Tierra Firme. In: Carlos Altamirano, ed. Los avatares de la "ciudad letrada" en el siglo XX. Vol. 2. Historia de los intelectuales en América Latina. Buenos Aires/Madrid: Katz Editores, 537-566.

Toury, Gideon (1995): Descriptive Translation Studies and beyond. Ámsterdam/Filadelfia: John Benjamins.

Venier, Martha, ed. (2008): Crónica Parcial: Cartas de Alfonso Reyes y Amado Alonso, 1927-1952. México: El Colegio de México.

Walsh, Thomas F. (1992): Katherine Anne Porter and Mexico. The Illusion of Eden. Austin: University of Texas Press.

Weinberg, Liliana (2014): Biblioteca Americana. Una poética de la cultura y una política de lectura. México: Fondo de Cultura Económica. 
Willson, Patricia (2008): El fin de una época: letrados-traductores en la primera colección de literatura traducida del siglo xx en la Argentina. Trans. Revista de Traductología. 12:29-42.

Willson, Patricia (2011): Los editores españoles y la traducción en la Argentina: desembarco en tierras fértiles. In: Andrea PAGNi, ed. El exilio republicano español en México y Argentina. Historia cultural, instituciones literarias, medios. Madrid: Iberoamericana/Vervuert, 145158.

\section{ANEXOS}

\section{Anexo 1: Colección Panamericana}

Aubert de Gaspé, Philippe (1863/1946): Los Antiguos Canadienses. (Traducido del francés por José Luis Izquierdo Hernández) In: Herbert Davis and Marine Leland, eds. Dos culturas canadienses; selecciones y reseña cultural de Canadá. Panamericana. Buenos Aires: W. M. Jackson, 1-207.

Brickell, Herschel, Poore, Dudley G. y Warfel, Harry R., eds (1945): Cuentistas Norteamericanos. Panamericana. Buenos Aires: W. M. Jackson.

Chandler Haliburton, Thomas (1836/1946): El relojero. (Traducido del francés por Alberto Gutiérrez Castro) In: Herbert Davis and Marine Leland, eds. Dos culturas canadienses; selecciones y reseña cultural de Canadá. Panamericana. Buenos Aires: W. M. Jackson, 209369.

Cunha Euclides (da) (1902/1945): Los Sertones. (Traducido del portugués por Benjamín DE Garay) Panamericana. Buenos Aires: W. M. Jackson.

Davis, Herbert and Leland, Marine, eds. (1946): Dos culturas canadienses; selecciones y reseña cultural de Canadá. Panamericana. Buenos Aires: W. M. Jackson.

Hawthorne, Nathaniel (1850/1945): La letra escarlata. (Traducido del inglés por Fernando Baeza Martos) Panamericana. Buenos Aires: W. M. Jackson.

Hibbert, Fernand (1905/1945): Sena. (Traducido del francés por Juan PARedes) Panamericana. Buenos Aires: W. M. Jackson.

Machado De Assis, Joaquim M. (1899/1945): Don Casmurro. Tres cuentos. (Traducido del portugués por Juan Natalicio GonzÁlez) Panamericana. Buenos Aires: W. M. Jackson.

Porter, Katherine-Anne (1922/1945): María Concepción. (Traducido del inglés por Alberto Gutiérrez Castro) In: Herschel Brickell, Dudley G. Poore y Harry R. Warfel, eds. Cuentistas Norteamericanos. Panamericana. Buenos Aires: W. M. Jackson, 431-455.

\section{Anexo 2: Paratextos}

Anónimo (1945): Propósito. In: Herschel Brickell, Dudley G. Poore y Harry R. Warfel, eds. Cuentistas Norteamericanos. Panamericana. Buenos Aires: W. M. Jackson, v-vi.

Brickel, Herschel (1945): Reseña Cultural. In: Herschel Brickell, Dudley G. Poore y Harry R. WARfel, eds. Cuentistas Norteamericanos. Panamericana. Buenos Aires: W. M. Jackson, vii-xxiv.

DAvis, Herbert (1946): Introducción a la literatura anglocanadiense. In: Herbert DAvis y Marine LeLAND, eds. Dos culturas canadienses; selecciones y reseña cultural de Canadá. Panamericana. Buenos Aires: W. M. Jackson Inc., xxxii-lxii.

Garay, Benjamín (de) (1945): Notas del Traductor. In: Euclides da Cunha. Los Sertones. (Traducido del portugués por Benjamín De Garay) Panamericana. Buenos Aires: W. M. Jackson, 521-530.

Gutiérrez Castro, Alberto (1945): Nota a pie de página. In: Herschel Brickell, Dudley G. Poore y Harry R. WARfel, eds. Cuentistas Norteamericanos. Panamericana. Buenos Aires: W. M. Jackson, 433.

Lee de Muñoz Marín, Muna (1945): Prologo. In: Nathaniel Hawthorne. La letra escarlata. (Traducido del inglés por Fernando Baeza Martos) Panamericana. Buenos Aires: W. M. Jackson, iii-xxi. 
Leland, Marine (1946): Introducción a la literatura francocanadiense. In: Herbert Davis y Marine Leland, eds. Dos culturas canadienses; selecciones y reseña cultural de Canadá. Panamericana. Buenos Aires: W. M. Jackson Inc., vi-xxxii.

Moraviah-Morpeau, Pierre (1945): Prólogo. In: Fernand Hibbert. Sena. (Traducido del francés por Juan PAREdes) Panamericana. Buenos Aires: W. M. Jackson, vii-xlvi.

Peixoto, Afranio (1945): Reseña cultural. In: Euclides da Cunha. Los Sertones. (Traducido del portugués por Benjamín DE GARAY) Panamericana. Buenos Aires: W. M. Jackson, vii-xxvi.

Pereira, Lúcia Miguel (1945): Prólogo. In: Joaquim M. Machado de Assis. Don Casmurro. Tres cuentos. (Traducido del portugués por Juan Natalicio González) Panamericana. Buenos Aires: W. M. Jackson, vii-xxxiv.

\section{Anexo 3: Obras originales de la Colección Panamericana}

Aubert de Gaspé, Philippe (1863): Les Anciens Canadiens. Québec: Desbarats et Derbishire. Chandler Haliburton, Thomas (1836): The Clockmaker. Halifax: Joshep Howe.

Cunha Euclides (da) (1902): Os Sertões. Rio de Janeiro: Laemmert \& Co.

Hawthorne, Nathaniel (1850): The Scarlet Letter. Boston: Ticknor, Reed \& Fields.

Hibbert, Fernand (1905): Séna. Port-au-Prince: Imprimerie de l’Abeille.

IRVING, Washington (1819/1885): Rip Van Winkle. In: Washington IRVING. The Sketch Book of Geoffrey Crayon, Gent. Chicago/Nueva York: Belford, Clarke \& Co., 37-54.

Machado de Assis, Joaquim M. (1899): Dom Casmurro. Rio de Janeiro/París: H. Garnier.

PoE, Edgar Allan (1839): The Fall of the House of Usher. In: William E. Burton and Edgar Allan PoE, eds. Burton's Gentleman's Magazine. Vol. 5. Filadelfia: William E. Burton, 145-152.

Porter, Katherine-Anne (1922): Maria Concepción. The Century Magazine. 105(2):224-239.

\section{Anexo 4: Otras obras y traducciones}

Hibbert, Fernand (1907): Scènes de la vie haïtienne: Les Thazar. Port-au-Prince: Imprimerie de l'Abeille.

Hibbert, Fernand (1908): Scènes de la vie haïtienne: Romulus. Port-au-Prince: Imprimerie de l'Abeille.

Hibbert, Fernand (1905/1977): Sena (Versión revisada por Roberto Romaní Velazco). Cuba: Casa de las Américas.

IRving, Washington (1819/1920): Rip Van Winkle. In: Nathaniel Hawthorne, Washington Irving, y Edward Everett Hale. Cuentos clásicos del norte. Segunda serie. (Traducido del inglés por Carmen Torres CALderón DE PINILLOS) Biblioteca Interamericana. Nueva York: Doubleday, Page \& Company, 11-44.

PoE, Edgar Allan (1839/1920): La caída de la casa de Usher. In: Edgar Allan PoE. Cuentos clásicos del norte. Primera serie. (Traducido del inglés por Carmen Torres Calderón DE PINILLos) Biblioteca Interamericana. Nueva York: Doubleday, Page \& Company, 75-106. 